\title{
High rate of transmission in a pulmonary tuberculosis outbreak in a primary school, north-eastern Italy, 2019
}

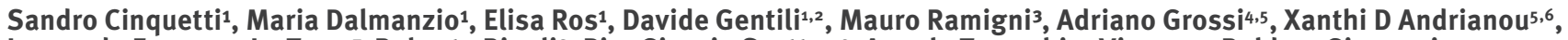
Leonardo Ermanno La Torre ${ }^{7}$, Roberto Rigoli8, Pier Giorgio Scotton ${ }^{9}$, Angela Taraschi ${ }^{10}$, Vincenzo Baldo ${ }^{11}$, Giuseppina

Napoletano ${ }^{12}$, Francesca Russo ${ }^{12}$, Patrizio Pezzotti5, Giovanni Rezza5, Antonietta Filia ${ }^{5}$

1. Public Health Office, Local Health Unit 2 Marca Trevigiana, Treviso, Italy

2. Department of Medical, Surgical and Experimental Sciences, University of Sassari, Sassari, Italy

3. Epidemiology Office, Local Health Unit 2 Marca Trevigiana, Treviso, Italy

4. University Cattolica del Sacro Cuore, Rome, Italy

5. Department of Infectious Diseases, National Health Institute (Istituto Superiore di Sanità), Rome, Italy

6. European Programme for Intervention Epidemiology Training (EPIET), European Centre for Disease Prevention and Control (ECDC), Stockholm, Sweden

7. Department of Radiology, Oderzo Hospital, Local Health Unit 2 Marca Trevigiana, Treviso, Italy

8. Department of Microbiology, Treviso Hospital, Local Health Unit 2 Marca Trevigiana, Treviso, Italy

9. Department of Infectious Diseases, Treviso Hospital, Local Health Unit 2 Marca Trevigiana, Treviso, Italy

10. Department of Pediatrics, Oderzo Hospital, Local Health Unit 2 Marca Trevigiana, Treviso, Italy

11. Hygiene and Public Health Unit, University of Padua, Padua, Italy

12. Prevention Department, Veneto Regional Health Authority, Venice, Italy

Correspondence: Antonietta Filia (antonietta.filia@iss.it)

Citation style for this article:

Cinquetti Sandro, Dalmanzio Maria, Ros Elisa, Gentili Davide, Ramigni Mauro, Grossi Adriano, Andrianou Xanthi D, La Torre Leonardo Ermanno, Rigoli Roberto, Scotton Pier Giorgio, Taraschi Angela, Baldo Vincenzo, Napoletano Giuseppina, Russo Francesca, Pezzotti Patrizio, Rezza Giovanni, Filia Antonietta. High rate of transmission in a pulmonary tuberculosis outbreak in a primary school, north-eastern Italy, 2019. Euro Surveill. 2019;24(24):pii=1900332. https://doi. org/10.2807/1560-7917.ES.2019.24.24.1900332

Italy is a low-incidence country for tuberculosis (TB). We describe a TB outbreak in a primary school in north-eastern Italy, involving 10 cases of active pulmonary disease and 42 cases of latent infection. The index case was detected in March 2019, while the primary case, an Italian-born schoolteacher, was likely infectious since January 2018. Administration of a preemployment health questionnaire to school staff with sustained contact with children should be considered in low-incidence countries.

Italy has low tuberculosis (TB) incidence, with a notification rate of 6.5 cases per 100,000 in 2017 [1,2], but outbreaks are occasionally described [3-7]. We report a large TB outbreak at a primary school in north-eastern Italy.

\section{Description of index case and source finding investigation}

On 5 March 2019, a case of childhood pulmonary TB was reported to the local health authority (LHA) in a town with a population of approximately 11,000 in the Veneto region (regional TB incidence of $6.2 / 100,000$ in 2017).

The school-aged child had been admitted to hospital for a diagnostic workup because of a 5-week history of fever, asthenia, productive cough, weight loss and diffuse peripheral lymphadenopathy. Prior to admission, the child had been diagnosed with influenza and acute frontal sinusitis, and had received antimicrobials (amoxicillin/clavulanic acid) for 10 days. On admission, the child underwent tuberculin skin testing (TST, Mantoux method: positive, $30 \mathrm{~mm}$ ), a chest X-ray (CXR) and chest computerised tomography (CT), and a presumptive diagnosis of TB was made. Gastric aspirate (GA) smear microscopy (three samples) was negative. Standard treatment for TB was started.

A source finding investigation was initiated immediately, using the 'progressive, concentric circles' (or 'stone-in-the-pond') approach [8], by screening household contacts, primary school classmates, schoolteachers and other close contacts of the child, defined as contacts with a cumulative exposure of 8 hours in a small space equivalent to a domestic space [9]. Screening was performed by clinical evaluation, TST and/or interferon gamma release assay (IGRA) testing (in case of previous vaccination or other conditions such as pregnancy, immunosuppression), and/or CXR, according to national guidelines [9]. A positive TST was defined as induration $>5 \mathrm{~mm}$. Persons with a positive TST underwent IGRA testing for confirmation, and CXR to exclude pulmonary active disease. Contacts with CXR abnormalities compatible with TB underwent further diagnostic evaluation, including CT, smear microscopy 
Timeline of the source finding and primary case contact investigations during a school tuberculosis outbreak, north-eastern Italy, 2019

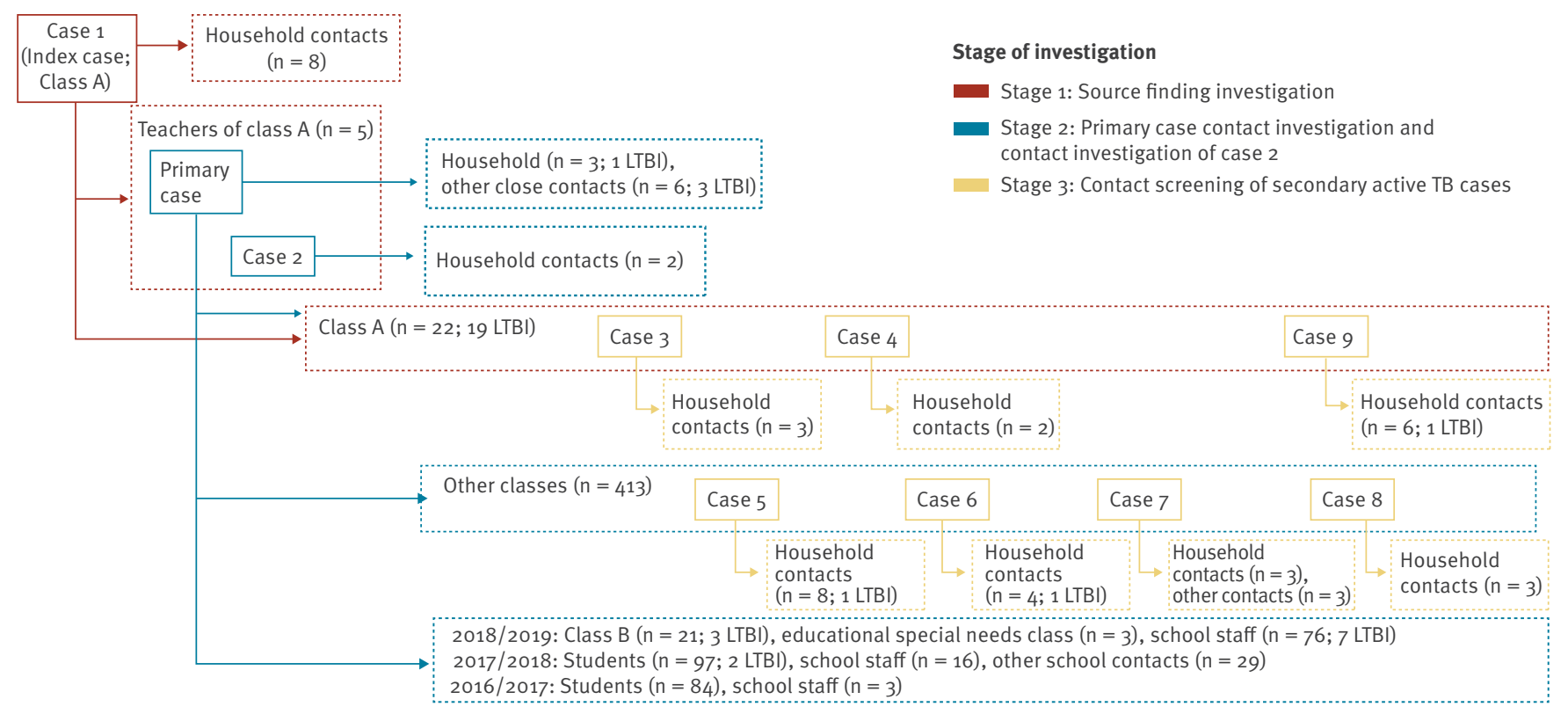

March 2019

April 2019

LTBI: latent tuberculosis infection; TB: tuberculosis.

The arrows do not indicate transmission but they connect each active TB case with the contacts screened around the case. The dashed boxes indicate the grouping of contacts and in each box we indicate the number of contacts screened in the group and the number of LTBI found. For each of the active cases, boxes with solid lines are used. The colours indicate the three different stages of the outbreak investigation.

and/or PCR (sputum or gastric aspirate specimens) and culture if appropriate. TST-positive children were also evaluated clinically by a paediatrician with infectious disease expertise.

As shown in Figure, a total of 35 close contacts of the child, including 22 classmates (class A), eight household contacts, and five teachers, were tested in the source finding investigation.

No cases of active TB nor latent tuberculosis infection (LTBI) were found among household contacts of the index case. One of the five schoolteachers, Italian-born, had a positive TST. This teacher reported a non-productive cough since 1 month and no other risk factors. CXR and PCR confirmed active pulmonary TB. Another teacher, despite a negative TST, appeared clinically unwell and reported cough, weight loss and asthenia since 9 months. This teacher therefore underwent further diagnostic evaluation, was found to have extensive cavitary TB, positive microscopy and culture, and was presumed to be the primary case. Drug susceptibility testing showed no resistance to all first-line antibiotics.
All 22 classmates of the index case (case 1) (class A) had a positive TST/IGRA. Four of six children with suspicious CXR findings, all asymptomatic, underwent CT to exclude active disease. Three were diagnosed with active pulmonary TB (Table 1, cases 3, 4 and 9). Gastric aspirate smear microscopy was negative in all three cases, two were culture-positive.

\section{Contact investigation around the primary case}

The primary case, Italian-born, was interviewed by experienced staff of the LHA, and reported a persistent cough since June 2018 , for which medical attention was sought on two occasions. The cough had been ascribed to smoking and chronic bronchitis, and two antibiotic courses with amoxicillin/clavulanic acid had been completed, 4 months and 1 month prior to diagnosis of TB. The primary case reported a previous positive TST as a child, but had not received preventive treatment.

The primary case taught class $A$, attended by the index case. The school was a two-story building. Students of class $A$, all screened in the previous step of the investigation, were considered close contacts, together with three household contacts and six friends/neighbours. 
Characteristics of active tuberculosis cases identified during a primary school outbreak, north-eastern Italy, 2019 ( $\mathrm{n}=10$ )

\begin{tabular}{|c|c|c|c|c|c|c|c|c|c|c|}
\hline Case & Description & Class & $\begin{array}{c}\text { Age } \\
\text { (years) }\end{array}$ & TB site & Symptoms & Chest X-ray & CT scan & Microscopy & PCR & Culture \\
\hline $\begin{array}{l}\text { Primary } \\
\text { case }\end{array}$ & Teacher & $A-B$ & $\geq 50$ & Pulmonary & $\begin{array}{c}\text { Persistent } \\
\text { productive } \\
\text { cough, weight } \\
\text { loss }\end{array}$ & Cavitary TB & $\begin{array}{l}\text { Cavitary TB, } \\
\text { bilateral } \\
\text { tree-in-bud }\end{array}$ & Positive & Positive & Confirmed \\
\hline $\begin{array}{l}\text { Case } 1 \\
\text { (index } \\
\text { case) }\end{array}$ & Student & A & $\leq 10$ & Pulmonary & $\begin{array}{c}\text { Fever, } \\
\text { persistent and } \\
\text { productive } \\
\text { cough, } \\
\text { asthenia, } \\
\text { anorexia } \\
\end{array}$ & $\begin{array}{c}\text { Bronchial } \\
\text { wall } \\
\text { thickening, } \\
\text { hilar } \\
\text { enlargement }\end{array}$ & $\begin{array}{c}\text { Multiple } \\
\text { enlarged } \\
\text { liquefactive } \\
\text { hilar lymph } \\
\text { nodes }\end{array}$ & Negative & Negative & Pending \\
\hline Case 2 & Teacher & $A-B$ & $\geq 50$ & Pulmonary & $\begin{array}{l}\text { Non-productive } \\
\text { cough, ( }(1 \\
\text { month) }\end{array}$ & $\begin{array}{l}\text { Minute } \\
\text { opacity }\end{array}$ & None & Negative & $\begin{array}{l}\text { Positive } \\
\text { (very low) }\end{array}$ & Pending \\
\hline Case 3 & Student & A & $\leq 10$ & Pulmonary & Asymptomatic & $\begin{array}{c}\text { Hilar } \\
\text { adenopathy }\end{array}$ & $\begin{array}{l}\text { Pulmonary } \\
\text { nodules }\end{array}$ & Negative & Negative & Confirmed \\
\hline Case 4 & Student & A & $\leq 10$ & Pulmonary & Asymptomatic & $\begin{array}{c}\text { Hilar } \\
\text { enlargement }\end{array}$ & $\begin{array}{c}\text { Pulmonary } \\
\text { nodule, } \\
\text { ipsilateral } \\
\text { hilar } \\
\text { adenopathy }\end{array}$ & Negative & Negative & Confirmed \\
\hline Case 5 & Student & C & $\leq 10$ & Pulmonary & Asymptomatic & $\begin{array}{c}\text { Parenchymal } \\
\text { infiltrate, } \\
\text { hilar } \\
\text { enlargement }\end{array}$ & None & Positive & $\begin{array}{l}\text { Positive } \\
\text { (very low) }\end{array}$ & Confirmed \\
\hline Case 6 & Student & D & $\leq 10$ & Pulmonary & Asymptomatic & $\begin{array}{c}\text { Hilar } \\
\text { adenopathy }\end{array}$ & $\begin{array}{c}\text { Small } \\
\text { patches } \\
\text { of lung } \\
\text { thickening, } \\
\text { multiple } \\
\text { enlarged } \\
\text { liquefactive } \\
\text { hilar lymph } \\
\text { nodes }\end{array}$ & Positive & $\begin{array}{l}\text { Positive } \\
\text { (very low) }\end{array}$ & Confirmed \\
\hline Case 7 & Student & $\mathrm{E}$ & $\leq 10$ & Pulmonary & Asymptomatic & $\begin{array}{c}\text { Hilar } \\
\text { adenopathy }\end{array}$ & $\begin{array}{c}\text { Pulmonary } \\
\text { nodule, } \\
\text { ipsilateral } \\
\text { hilar } \\
\text { adenopathy }\end{array}$ & Negative & $\begin{array}{l}\text { Positive } \\
\text { (very low) }\end{array}$ & Confirmed \\
\hline Case 8 & Student & C & $\leq 10$ & Pulmonary & Asymptomatic & $\begin{array}{c}\text { Hilar } \\
\text { adenopathy }\end{array}$ & $\begin{array}{c}\text { Subpleural } \\
\text { lung spots, } \\
\text { hilar } \\
\text { adenopathy }\end{array}$ & Negative & Negative & Pending \\
\hline Case 9 & Student & A & $\leq 10$ & Pulmonary & Asymptomatic & $\begin{array}{l}\text { Parenchymal } \\
\text { infiltrate }\end{array}$ & $\begin{array}{l}\text { Pulmonary } \\
\text { nodule, } \\
\text { multiple hilar } \\
\text { lymph nodes }\end{array}$ & Negative & Negative & Pending \\
\hline
\end{tabular}

CT: computerized tomography; TB: tuberculosis

One household contact, two neighbours and one friend were TST-positive, none had active TB.

Besides teaching class $A$, the primary case reported spending 6 hours per week leading workshops for classes $A$ and $B$, and taught students with special educational needs. The investigation was therefore extended (Figure): three of 21 class B students were TST-positive, all had a normal CXR (Table 2).

In view of these findings, the extent of disease and duration of symptoms of the primary case, a decision was made to screen the entire school population
(Figure). Four additional active TB cases were identified (Table 1 and Table 2). The investigation was therefore further extended, first to students and staff who had attended or worked in the school in the previous school year (2017/2018), and subsequently to those of school year 2016/2017. Of 97 students and 16 school staff of school year 2017/2018 tested (who no longer attended or worked in the school), two were TST-positive (both had negative (XR), while none of the students and staff of 2016/2017 were TST-positive (Figure; Table 2).

In total, 10 cases of active TB disease were identified, seven were female and three were male. Two cases 
TABLE 2

Attack rates for latent and active tuberculosis among screened contacts of the primary case in a school outbreak, northeastern Italy, $2019(\mathrm{n}=691)$

\begin{tabular}{|c|c|c|c|c|c|c|c|c|c|c|c|}
\hline \multirow{2}{*}{$\begin{array}{l}\text { Contacts of primary case } \\
\text { screened }\end{array}$} & \multirow{2}{*}{$\begin{array}{l}\text { Number at } \\
\text { risk }\end{array}$} & \multirow{2}{*}{$\begin{array}{l}\text { Number } \\
\text { screened }\end{array}$} & \multicolumn{3}{|c|}{ LTBI } & \multicolumn{3}{|c|}{ Active } & \multicolumn{3}{|c|}{ Infected } \\
\hline & & & $\mathrm{n}$ & $\%$ & $(95 \% \mathrm{Cl})$ & $\mathrm{n}$ & $\%$ & $(95 \% \mathrm{Cl})$ & $\mathrm{n}$ & $\%$ & $(95 \% \mathrm{Cl})$ \\
\hline \multicolumn{12}{|l|}{ School contacts } \\
\hline \multicolumn{12}{|c|}{ Students and staff of school (school year 2018/19) } \\
\hline Class $A^{a}$ & 23 & 23 & 19 & 82.6 & $(61-95)$ & 4 & 17.4 & $(5-39)$ & 23 & 100.0 & $(85-100)$ \\
\hline 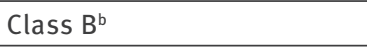 & 21 & 21 & 3 & $14 \cdot 3$ & $(3-36)$ & 0 & 0.0 & $(0-16)$ & 3 & 14.3 & $(3-36)$ \\
\hline Students with special needs & 3 & 3 & 0 & 0.0 & $(0-71)$ & 0 & 0.0 & $(0-71)$ & 0 & 0.0 & $(0-71)$ \\
\hline Other classes ${ }^{c}$ & 413 & 413 & 7 & 1.7 & $(1-3)$ & 4 & 1.0 & $(0-2)$ & 11 & 2.7 & $(1-5)$ \\
\hline School staff & 80 & 80 & 7 & 8.8 & $(4-17)$ & 1 & 1.3 & $(0-7)$ & 8 & 10.0 & $(4-19)$ \\
\hline Subtotal & 540 & 540 & 36 & 6.7 & $(5-9)$ & 9 & 1.7 & $(1-3)$ & 45 & 8.3 & $(6-11)$ \\
\hline \multicolumn{12}{|c|}{ Previous students and staff of school (school year 2017/18) } \\
\hline School graduates 2018 & 99 & 97 & 2 & 2.1 & $(0-7)$ & 0 & 0.0 & $(0-4)$ & 2 & 2.1 & $(0-7)$ \\
\hline School staff & 18 & 16 & 0 & 0.0 & $(0-21)$ & 0 & 0.0 & $(0-21)$ & 0 & 0.0 & $(0-21)$ \\
\hline Other contacts & 29 & 29 & 0 & 0.0 & $(0-12)$ & 0 & 0.0 & $(0-12)$ & 0 & 0.0 & $(0-12)$ \\
\hline Subtotal & 146 & 142 & 2 & 1.4 & $(0-5)$ & 0 & 0.0 & $(0-3)$ & 2 & 1.4 & $(0-5)$ \\
\hline \multicolumn{12}{|l|}{ Other close contacts } \\
\hline Household contacts & 3 & 3 & 1 & 33.3 & $(1-91)$ & 0 & 0.0 & $(0-71)$ & 1 & 33.3 & $(1-91)$ \\
\hline Friends, neighbours & 6 & 6 & 3 & 50.0 & $(12-88)$ & 0 & 0.0 & $(0-46)$ & 3 & 50.0 & $(12-88)$ \\
\hline Subtotal & 9 & 9 & 4 & 44.4 & $(14-79)$ & 0 & 0.0 & $(0-34)$ & 4 & 44.4 & $(14-79)$ \\
\hline Total & 695 & 691 & 42 & 6.1 & $(4-8)$ & 9 & 1.3 & $(1-2)$ & 51 & 7.4 & $(6-10)$ \\
\hline
\end{tabular}

$\mathrm{Cl}$ : confidence interval; LTBI: latent tuberculosis infection.

a Including the index case and 22 classmates. Two children were previously vaccinated.

${ }^{b}$ Including two children born in high-incidence countries. One vaccinated and one unvaccinated.

' Including 14 children born in high-incidence countries, one Italian-born child residing with a foreign-born parent from a high-incidence country and 15 foreign-born vaccinated children.

were teachers (one of whom was the primary case) and eight were students (four of class $A$ and four attending other classes) (Figure; Table 1). Strain testing is currently ongoing. In addition, 31 children, seven teachers, and four close contacts of the primary case were diagnosed with LTBI and were prescribed preventive treatment with isoniazid (Table 2). Two of eight children with pulmonary TB and eight of 31 children with LTBI were either foreign-born or resided in households with foreign-born parents (from high incidence countries). None of the foreign-born parents or other household contacts of these children reported a TB history. Table 2 shows attack rates observed in the outbreak. As shown in the table, $100 \%$ of children attending class $A$ were infected.

\section{Discussion}

To our knowledge, this is one of the largest TB school outbreaks detected in Italy in the last 10 years. All cases are considered to have been infected by one of the schoolteachers of class A (primary case), who was Italian-born and had probably been infected as a child when TB incidence in Italy was much higher than it is currently. Molecular typing results will allow us to definitely determine if the cases are all linked. TST results of students attending the school in previous school years suggest that the primary case was infectious since January 2018.
It is unlikely that the second schoolteacher with pulmonary TB was a source of infection in this outbreak as this teacher had a non-productive cough and negative sputum microscopy, and was symptomatic since only 1 month. Likewise, considering that young children are usually not infectious, we doubt that any of them transmitted the infection. Although we consider it improbable, we cannot exclude with absolute certainty that the children with $\mathrm{LTBI}$ residing in households with foreignborn parents from higher incidence countries may have been previously infected during visits to these countries. Considering the schoolteacher's degree of infectivity and duration of symptoms, we expect molecular investigation results to confirm that both children with active TB residing in foreign born families were infected at the school.

The major factor that contributed to this outbreak was delayed diagnosis of the primary case, leading to prolonged exposure of school children and other close contacts, and extensive transmission of the disease. Delayed diagnosis of TB is frequent in outbreaks in low-incidence countries and such a delay occurred also with the index case $[4,10,11]$. In a recent Italian study, delayed diagnosis of TB occurred more frequently in Italian-born compared with foreign-born cases [12]. Increased awareness of TB is warranted even in lowincidence countries, especially among primary care 
physicians, and TB should be included in the differential diagnosis of persistent cough, particularly in presence of other symptoms such as unintentional weight loss, fatigue, fever and night sweats.

The contact investigation was conducted by experienced staff of the local public health department and almost all (99.4\%) contacts eligible for screening were tested. Effective communication, including face-to-face meetings, with parents, school staff and the public was key in building trust and achieving a high rate of participation. Only one person of 695 did not accept to be tested. The remaining three who were not tested during the school contact investigation had moved to other Italian regions: two have been traced and were tested locally (results pending).

The estimated attack rate in this outbreak was very high for close school contacts. Nineteen of 23 children $(82.6 \%)$ in class A were diagnosed with LTBI and four of $23(17.4 \%)$ with active pulmonary TB. On the other hand, if we consider all screened contacts, the overall attack rate, seems to be slightly lower compared with other documented outbreaks in Italian schools in the last 10 years $[3,4]$ or in other congregate children settings [13]. This may be due to the limited number of close contacts of the primary case but also to the fact that screening was extended to other-than-close contacts. Contacts with a negative TST at initial investigation will be tested again 10 weeks after the last contact with the primary case.

Currently in Italy, health assessments of primary school employees are not regulated by national law. These assessments are performed mainly from an occupational health perspective that aims to protect employees rather than from a public health perspective that aims to avoid transmission. As already done within the child care system in Sweden [14] and the United States (e.g. in California, at all levels of schooling), the administration of a health questionnaire to school staff who have sustained contact with children should be considered in an effort to identify persons at risk for TB infection (e.g. close contact of someone with infectious TB during lifetime, history of positive TST, birth in a country with an elevated TB incidence) $[4,14,15]$. The questionnaire could be administered at the stage of employment, to school staff working with children (including staff of nursery schools and child care centres), in order to identify those with risk factors for TB to whom targeted testing (with a TST, IGRA and/ or (XX) could be proposed. Based on the screening result, occupational health services staff could determine the need for further evaluation and/or preventive treatment, and decide on the frequency of repeat risk assessments. As highlighted by other authors, besides identifying persons to be screened, the use of such a questionnaire would also provide an opportunity to increase TB awareness among school staff [14].
Improved timeliness of diagnosis of TB is essential to reduce the risk for outbreaks, and timely and efficient investigation of TB outbreaks is fundamental to ensure early detection of TB infection. A recent European Centre for Disease Prevention and Control (ECDC) assessment suggests that information on TB incidents affecting children in congregate settings is not systematically collected and analysed although this would be useful to assess that adequate responses are in place and to share lessons learned in order to improve future source and contact investigations [8].

\section{Ethical statement}

This investigation was part of a routine public health response to a school outbreak and did not require ethics committee approval.

\section{Conflict of interest}

None declared.

\section{Authors' contributions}

SC, AF, ER and DG drafted the manuscript. SC supervised and coordinated the multidisciplinary outbreak response team, made up of MD, ER, DG, MR, LELT, RR, PGS and AT, and of all public health measures undertaken during the outbreak. MD led the school outbreak investigation and contact tracing activities. ER and DG collected and analysed data. MR contributed to coordination of the outbreak investigation. LELT, RR, PGS and AT performed clinical evaluations of cases and contacts. AG and XDA contributed to data collection and analysis, and to preparing the manuscript. XDA prepared the Figure. VB, FR and GN contributed to coordination of activities. GR, PP and AF provided technical support to the outbreak investigation team. PP and GR contributed to revising the manuscript, AF finalised the manuscript. All authors read and approved the final manuscript.

\section{References}

1. World Health Organization (WHO). Towards TB elimination in low-incidence countries. Geneva: WHO. [Accessed: 2019 April 23]. Available from: http://www.who.int/tb/areas-of-work/ treatment/elimination/en/

2. WHO Regional Office for Europe (WHO/Europe)/European Centre for Disease Prevention and Control (ECDC). Tuberculosis surveillance and monitoring in Europe, 2019 - 2017 data. Copenhagen: WHO/Euro; 2019. [Accessed: 2019 April 23]. Available from: https://ecdc.europa.eu/en/publications-data/ tuberculosis-surveillance-and-monitoring-europe-2019

3. Faccini M, Codecasa LR, Ciconali G, Cammarata S, Borriello CR, De Gioia C, et al. Tuberculosis outbreak in a primary school, Milan, Italy. Emerg Infect Dis. 2013;19(3):485-7. https://doi. org/10.3201/eid1902.120527 PMID: 23621942

4. Filia A, Ciarrocchi G, Belfiglio R, Caferri M, Bella A, Piersimoni C, et al. Tuberculosis in kindergarten and primary school, Italy, 2008-2009. Emerg Infect Dis. 2011;17(3):514-6. https://doi. org/10.3201/eid1703.101440 PMID: 21392447

5. Luzzati R, Migliori GB, Zignol M, Cirillo DM, Maschio M, Tominz $R$, et al. Children under 5 years are at risk for tuberculosis after occasional contact with highly contagious patients: outbreak from a smear-positive healthcare worker. Eur Respir J. 2017;50(5):1701414. https://doi.org/10.1183/13993003.014142017 PMID: 29097434

6. Borgia P, Cambieri A, Chini F, Coltella L, Delogu G, Di Rosa E, et al. Suspected transmission of tuberculosis in a maternity ward from a smear-positive nurse: preliminary results of clinical evaluations and testing of neonates potentially exposed, Rome, Italy, 1 January to 28 July 2011. Euro Surveill. 
2011;16(40):19984. https://doi.org/10.2807/ese.16.40.19984en PMID: 21996378

7. Faccini M, Cantoni S, Ciconali G, Filipponi MT, Mainardi G, Marino AF, et al. Tuberculosis-related stigma leading to an incomplete contact investigation in a low-incidence country. Epidemiol Infect. 2015;143(13):2841-8. https://doi.org/10.1017/ So95026881400394X PMID: 25600903

8. European Centre for Disease Prevention and Control (ECDC). Investigation and control of tuberculosis incidents affecting children in congregate settings. Stockholm: ECDC; 2013. Available from: https://ecdc.europa.eu/sites/portal/files/ media/en/publications/Publications/guidance-investigationcontrol-tb-incidents-children-in-congregate-settings.pdf

9. Ministero della Salute. Aggiornamento delle raccomandazioni per le attività di controllo della tubercolosi - anno 2010. [Updated recommendations for tuberculosis control - 2010]. Rome: Ministero della Salute; 2010. [Accessed: 24 Apr 2019]. Italian. Available from: http://www.salute.gov.it/portale/ documentazione/p6_2_2_1.jsp?lingua=italiano\&id=1661

10. Wang S-H, Hunt WG, Powell DA. Lessons learned from two school tuberculosis investigations. J Immigr Minor Health. 2010;12(6):853-8. https://doi.org/10.1007/s10903-008-9220-9 PMID: 19127432

11. Golesi F, Brignatz J, Bellenfant M, Raoult D, Drancourt M. Mycobacterium tuberculosis Beijing outbreak in a school in Marseille, France, 2012. Euro Surveill. 2013;18(2):20354. PMID: 23324426

12. Pezzotti P, Pozzato S, Ferroni E, Mazzocato V, Altieri AM, Gualano G, et al. Delay in diagnosis of pulmonary tuberculosis: a survey in the Lazio region, Italy. Epidemiol Biostat Public Health. 2015 ;12(1).

13. Schepisi MS, Motta I, Dore S, Costa C, Sotgiu G, Girardi E. Tuberculosis transmission among children and adolescents in schools and other congregate settings: a systematic review. New Microbiol. 2019;41(4):282-90. PMID: 30252926

14. Gillman A, Berggren I, Bergström SE, Wahlgren H, Bennet R. Primary tuberculosis infection in 35 children at a Swedish day care center. Pediatr Infect Dis J. 2008;27(12):1078-82. https:// doi.org/10.1097/INF.ob013e31817e83f4 PMID: 18946364

15. California Department of Public Health (CDPH). California School Employee Tuberculosis (TB) Risk Assessment Questionnaire. Sacramento: CDPH; 2018. Available from: https://www.cdph.ca.gov/Programs/CID/DCDC/CDPH\%20 Document\%2oLibrary/TBCB-CA-School-Staff-Volunteer-TBRisk-Assessment.pdf

\section{License, supplementary material and copyright}

This is an open-access article distributed under the terms of the Creative Commons Attribution (CC BY 4.0) Licence. You may share and adapt the material, but must give appropriate credit to the source, provide a link to the licence and indicate if changes were made.

Any supplementary material referenced in the article can be found in the online version.

This article is copyright of the authors or their affiliated institutions, 2019. 